\title{
Danio rerio as a model in aquatic toxicology and sediment research
}

\author{
H. Hollert ${ }^{1} \cdot$ Steffen H. Keiter ${ }^{1,2}$
}

Received: 29 August 2015 / Accepted: 2 September 2015 /Published online: 15 September 2015

(C) Springer-Verlag Berlin Heidelberg 2015

Worldwide, the zebrafish (Danio rerio) has become a prominent model for biomedical research and (eco)toxicology (Strähle et al. 2012). Within favourable conditions, female fish are able to spawn year round every $2-3$ days. They spawn up to 200 eggs with a transparent chorion per female. This characteristic makes them a very suitable test organism in biology as their larval development can be observed readily (Scholz et al. 2008). Additionally, zebrafish are easily obtainable, maintainable and inexpensive (Braunbeck et al. 2015) and suitable for being used as an effectbased monitoring tool under the water framework directive (Wernersson et al. 2015).

In our society, we have a high use of chemicals that spread across the world with potential health risks for humans and wildlife. Many of these compounds enter the aquatic system and accumulate in sediments and represent multi-component chemical "cocktails" of pollutants posing different threats not only to wildlife but also to humans. Under regular environmental conditions, organisms can be exposed to multiple chemicals associated with different risks and specific effects, e.g. teratogenicity, immune toxicity and suppression, genotoxicity

Responsible editor: Philippe Garrigues

H. Hollert

Henner.Hollert@bio5.rwth-aachen.de

Steffen H. Keiter

Steffen.Keiter@oru.se

1 Department of Ecosystem Analysis, Institute for Environmental Research (Biology V), RWTH Aachen University, Worringerweg 1, 52074 Aachen, Germany

2 Man-Technology-Environment Research Centre, School of Science and Technology, Örebro University, 70182 Örebro, Sweden and endocrine disruption. Moreover, it has been repeatedly demonstrated that pollutants and the underlying toxic responses may interact and generate effects that are different from the toxicity of the individual chemicals. However, at the present time, risk assessment and evaluation of chemicals is mainly based on risks that can be posed by single chemicals. On the other hand, risk assessments of environmental samples are mostly limited to the chemical analyses of the present pollutions.

Understanding the effects of mixture toxicity, generally referred to as "cocktail effects," represents one of today's greatest challenges not only in environmental but also in human toxicology. In addition, there is a dire need to develop novel biological test systems and test strategies which can be used for risk assessment of complex environmental samples. Future risk assessment strategies should integrate toxicological endpoints and chemical analysis in order to identify the chemicals causing a threat for the environment. Zebrafish is one of only a few fish species whose genome is sequenced and publicly available and can be also used for investigating mechanism-specific effects. This allows the usage of zebrafish in environmental studies which can provide information regarding the molecular mechanism and related morphological alterations of an organism to changing environmental conditions. Moreover, many of the critical pathways that regulate vertebrate development are highly conserved between humans and zebrafish, and approximately, $70 \%$ of all genes associated with diseases in humans have functional homologs in zebrafish (Langheinrich 2003). Thus, zebrafish represents a prominent model organism to investigate the health risks of pollutants towards humans and the environment. 
Particularly, the use of embryos is receiving increasing attention, since they are considered as replacement method for animal experiments. Zebrafish embryos allow the analysis of multiple endpoints ranging from acute and developmental toxicity determination to complex functional genetic and physiological analysis (Strähle et al. 2012). The zebrafish as a model organism has received an increasing relevance for (eco)toxicological risk assessment of chemicals and complex environmental mixtures to predict acute toxicity (Braunbeck et al. 2015). Zebrafish embryos also provide the possibility to investigate molecular and mechanism-specific alterations to measure the bioavailable hazard potential of contaminated sediments (Hallare et al. 2011; Vincze et al. 2014) or fractions of effect-directed analyses (Di Paolo et al. 2015).

Recently, also a Special Issue of Environmental Science and Pollution Research was published elucidating the interactions and adverse effects of PAHs and fish from molecular to individual level (Cousin and Cachot 2014). In particular, the primary importance of sediment-borne toxicity and specific underlying mechanisms of PAH contamination has been emphasized as such hydrophobic compounds are mainly associated with suspended particular matter and, thus, accumulate in sediments.

This Special Issue of Environmental Science and Pollution Research highlights selected papers presented at the international symposium on "Methods for the assessment of sediment toxicity using zebrafish (Danio rerio)" held at RWTH Aachen University in 2013. Moreover, the present issue aims at presenting the novel results of the joint research project DanTox and for a scientific exchange on recent cutting-edge research using the zebrafish as a prominent model organism in environmental science.

Within the DanTox project (funded by the German Federal Ministry of Education and Research, BMBF from 2010 to 2013), existing assays could be developed further (Garcia-Käufer et al 2015, Hafner et al. 2015), and novel mechanism-specific contact assays were introduced for a comprehensive assessment of the bioavailable toxicity in sediments (Bräunig et al. 2015; Keiter et al. 2010; Kais et al. 2015; Schiwy et al. 2015). New and valuable knowledge concerning the application of such bioassays and the underlying cellular mechanisms have been gained. Moreover, microarray analyses were proven to be able to identify sets of genes, which represent various important cellular pathways and react to environmental contaminants (Hausen et al. 2015).

In detail, 15 papers on the development of novel molecular and mechanism-specific bioassays are presented in this special issue elucidating the following topics:
- Braunbeck et al. (2015) reviews origin, applications and future of the fish embryo test (FET)

- A review on the zebrafish as a model to study the role of DNA methylation in environmental toxicology (Kamstra et al. 2015)

- A review on comparability of behavioural assays using zebrafish larvae to assess neurotoxicity (Legradi et al. 2015)

- Bio-accumulation and molecular effects of sedimentbound metals in zebrafish embryos (Redelstein et al. 2015)

- Development of a novel contact assay for testing arylhydrocarbon receptor (AhR)-mediated toxicity of chemicals and whole sediments in zebrafish (Danio rerio) embryos (Schiwy et al. 2015)

- Fish embryo tests with Danio rerio as a tool to evaluate the efficiency of waste water treatment plants with respect to the reduction of embryotoxic potentials in surface water and sediment (Thellmann et al. 2015)

- Impact of Prochloraz on masculinization of zebrafish (Danio rerio) (Baumann et al. 2015)

- Investigations of BFCOD activity in fish cell lines and zebrafish embryos and its modulation by chemical ligands of aryl hydrocarbon and nuclear receptors (Creusot et al. 2015)

- Investigations of acetylcholinesterase in zebrafish embryos as a tool to identify neurotoxic substances in sediments (Kais et al. 2015)

- Experiments on genotoxic and teratogenic effects of freshwater sediment samples from Rhine and Elbe River (Germany) in zebrafish embryo using a multi-endpoint testing strategy (Garcia-Käufer et al. 2015)

- Larval behavioral disruption in offspring of zebrafish exposed through diet to three environmentally relevant mixtures of PAHs and long term effects of a pyrolytic mixture (Vignet et al. 2015)

- A study on time dependent expression and activity of cytochrome P450 1s in early life-stages of the zebrafish (Danio rerio) (Bräunig et al. 2015)

- Development of a threshold-screening ANOVA as an algorithm to unmask hidden gene expression patterns in aggregated noisy transcriptome data (Hausen et al. 2015)

- Investigations on the toxicity of sediment cores from Yangtze River estuary to zebrafish (Danio rerio) embryos (Wang et al. 2015)

- Investigations on sediment toxicity of German rivers applying a standardized bioassay battery (Hafner et al. 2015)

Acknowledgments The authors would like to thank the Federal Ministry of Education and Research, Germany (BMBF), for supporting the research cluster DanTox. 


\section{References}

Baumann L, Knörr S, Keiter S, Nagel T, Segner H, Braunbeck T (2015): Prochloraz causes irreversible masculinization of zebrafish (Danio rerio). Environ Sci Pollut Res, 1-6. doi:10.1007/s11356-014-3486-3

Braunbeck T, Kais B, Lammer E, Otte J, Schneider K, Stengel D, Strecker R (2015): The fish embryo test (FET): origin, applications, and future. Environ Sci Pollut Res. 1-15. doi:10.1007/s11356-014-3814-7

Bräunig J, Schiwy S, Broedel O, Müller Y, Frohme M, Hollert H, Keiter S (2015): Time-dependent expression and activity of cytochrome P450 1s in early life-stages of the zebrafish (Danio rerio). Environ Sci Pollut Res. 1-10. doi:10.1007/s11356-015-4673-6

Cousin X, Cachot J (2014) PAHs and fish - exposure monitoring and adverse effects - from molecular to individual level. Environ Sci Pollut Res 21:13685-13688

Creusot N, Brion F, Piccini B, Budzinski H, Porcher JM, Aït-Aïssa S (2015): BFCOD activity in fish cell lines and zebrafish embryos and its modulation by chemical ligands of human aryl hydrocarbon and nuclear receptors. Environ Sci Pollut Res. 1-12

Di Paolo C, Seiler T-B, Keiter S, Hu M, Muz M, Brack W, Hollert H (2015) The value of zebrafish as an integrative model in effect-directed analysis - a review. Environ Sci Eur 27:8. doi:10.1186/s12302-015-0040-y

Garcia-Käufer M, Gartiser S, Hafner C, Schiwy S, Keiter S, Gründemann C, Hollert H (2015) Genotoxic and teratogenic effect of freshwater sediment samples from the Rhine and Elbe River (Germany) in zebrafish embryo using a multi-endpoint testing strategy. Environ Sci Pollut Res. 1-17. doi:10.1007/s11356-014-3894-4

Hafner C, Gartiser S, Garcia-Käufer M, Schiwy S, Hercher C, Meyer W, Achten C, Larsson M, Engwall M, Keiter S, Hollert H (2015) Investigations on sediment toxicity of German rivers applying a standardized bioassay battery. Environ Sci Pollut Res. 1-13. doi: 10.1007/s11356-015-4482-y

Hallare AV, Seiler TB, Hollert H (2011) The versatile, changing, and advancing roles of fish in sediment toxicity assessment - a review. J Soils Sediments 11:141-173

Hausen J, Otte JC, Strahle U, Hammers-Wirtz M, Hollert H, Keiter SH, Ottermanns R (2015) Fold-change threshold screening: a robust algorithm to unmask hidden gene expression patterns in noisy aggregated transcriptome data. Environ Sci Pollut Res. doi:10.1007/ s11356-015-5019-0

Kais B, Stengel D, Batel A, Braunbeck T (2015) Acetylcholinesterase in zebrafish embryos as a tool to identify neurotoxic effects in sediments. Environ Sci Pollut Res. 1-11. doi:10.1007/s11356-014-4014-1

Kamstra J, Aleström P, Kooter J, Legler J (2015) Zebrafish as a model to study the role of DNA methylation in environmental toxicology. Environ Sci Pollut Res. 1-15. doi:10.1007/s11356-014-3466-7

Keiter S, Peddinghaus S, Feiler U, von der Goltz B, Hafner C, Ho NY, Rastegar S, Otte JC, Ottermanns R, Reifferscheid G, Strähle U, Braunbeck T, Hammers-Wirtz M, Hollert H (2010) DanTox-a novel joint research project using zebrafish (Danio rerio) to identify specific toxicity and molecular modes of action of sediment-bound pollutants. J Soils Sediments 10:714-717

Langheinrich (2003) Bioessays, 25, 904-912

Legradi J, el Abdellaoui N, van Pomeren M, Legler J (2015) Comparability of behavioural assays using zebrafish larvae to assess neurotoxicity. Environ Sci Pollut Res. 1-13. doi:10.1007/s11356-014-3805-8

Redelstein R, Zielke H, Spira D, Feiler U, Erdinger U, Zimmer H, Wiseman S, Hecker M, Giesy JP, Seiler TB, Hollert H (2015) Bio-accumulation and molecular effects of sediment-bound metals in zebrafish Tembryos. Environ Sci Pollut Res. doi:10.1007/s11356-015-5328-3

Schiwy S, Bräunig J, Alert H, Hollert H, Keiter S (2015) A novel contact assay for testing aryl hydrocarbon receptor (AhR)-mediated toxicity of chemicals and whole sediments in zebrafish (Danio rerio) embryos. Environ Sci Pollut Res. 1-14. doi:10.1007/s11356-014-3185-0
Scholz S, Fischer S, Gundel U, Kuster E, Luckenbach T, Voelker D (2008) The zebrafish embryo model in environmental risk assessment-applications beyond acute toxicity testing. Environ Sci Pollut Res 15:394-404

Strähle U, Scholz S, Geisler R, Greiner P, Hollert H, Rastegar S, Schumacher A, Selderslaghs I, Weiss C, Witters H, Braunbeck T (2012) Zebrafish embryos as an alternative to animal experiments a commentary on the definition of the onset of protected life stages in animal welfare regulations. Reprod Toxicol 33:128-132

Thellmann P, Köhler H-R, Rößler A, Scheurer M, Schwarz S, Vogel H-J, Triebskorn R (2015) Fish embryo tests with Danio rerio as a tool to evaluate surface water and sediment quality in rivers influenced by wastewater treatment plants using different treatment technologies. Environ Sci Pollut Res. 1-12. doi:10.1007/s11356-014-3785-8

Vignet C, Joassard L, Lyphout L, Guionnet T, Goubeau M, Le Menach K, Brion F, Kah O, Chung B-C, Budzinski H, Bégout M-L, Cousin X (2015) Exposures of zebrafish through diet to three environmentally relevant mixtures of PAHs produce behavioral disruptions in unexposed F1 and F2 descendant. Environ Sci Pollut Res. 1-13

Vincze K, Graf K, Scheil V, Koehler H-R, Triebskorn R (2014): Embryotoxic and proteotoxic effects of water and sediment from the Neckar River (Southern Germany) to zebrafish (Danio rerio) embryos. Environmental Sciences Europe 26. doi:10.1186/21904715-26-3

Wang P, Zhang L, Liu L, Chen L, Gao H, Wu L (2015) Toxicity of sediment cores from Yangtze River estuary to zebrafish (Danio rerio) embryos. Environ Sci Pollut Res. 1-11. doi:10.1007/s11356014-3484-5

Wernersson A-S, Carere M, Maggi C, Tusil P, Soldan P, James A, Sanchez W, Dulio V, Broeg K, Reifferscheid G, Buchinger S, Maas H, Van Der Grinten E, O'Toole S, Ausili A, Manfra L, Marziali L, Polesello S, Lacchetti I, Mancini L, Lilja K, Linderoth M, Lundeberg T, Fjallborg B, Porsbring T, Larsson DGJ, Bengtsson-Palme J, Forlin L, Kienle C, Kunz P, Vermeirssen E, Werner I, Robinson CD, Lyons B, Katsiadaki I, Whalley C, den Haan K, Messiaen M, Clayton H, Lettieri T, Carvalho RN, Gawlik BM, Hollert H, Di Paolo C, Brack W, Kammann U, Kase R (2015) The European technical report on aquatic effect-based monitoring tools under the water framework directive. Environ Sci Eur 27:1-11. doi:10.1186/s12302-015-0039-4

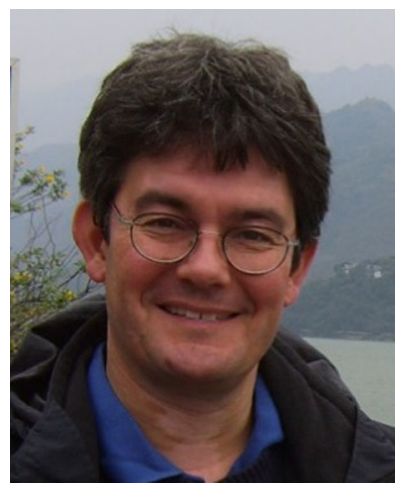

Henner Hollert is full professor and director of the Department for Ecosystem Analysis, Institute of Environmental Research, RWTH Aachen University, Germany. Furthermore, he is adjunct professor at the Universities of Chongqing, Nanjing and Tongji University in Shanghai (China).

$\mathrm{He}$ is expert in bioanalytical environmental toxicology, aquatic toxicology, development and validation of in vitro bioassays, sediment and soil toxicology, wasteand ground water investigations, effect-directed analysis and weight-of-evidence approaches. From 2010-2013 he was the speaker and one of the PIs of the joint project DanTox (funded by the German Federal Ministry of Education and Research). He is one of the PIs within the German Excellence Cluster Tailor made fuels from biomass at RWTH Aachen University, head of the working group on bioassays in the European Norman Network and one of the co-authors of the report on effect based tools of the European Commission. 
In 2012 he was chair of the local organizing committee of the SETAC World Congress in Berlin and one of the organizers of the German-American Frontiers of Science Symposia (US National Academy of Science and Humboldt Foundation). He is council member of the Society Environmental Toxicology and Chemistry, Europe-German Language Branch (president in 2004) and is one of the Core group members of BioSC (Bioeconomy Science Centre).

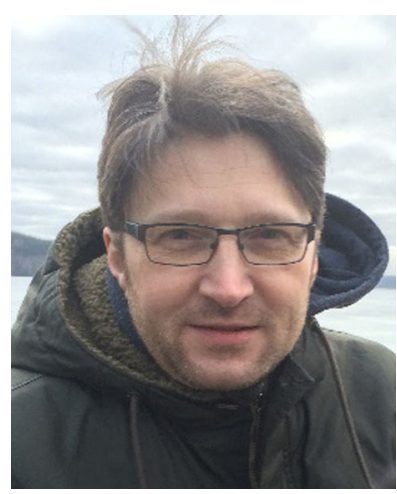

Steffen Keiter is assistant professor at MTM Research Centre, Örebro University, Sweden. He received his Ph.D. in Biology in 2007 at Heidelberg University. He investigated different compartments of the Danube River in order to serve an explanation to the local fish decline using a comprehensive Weight-of-Evidence approach. Steffen Keiter has authored 29 international and national peer-reviewed publications. His research is focusing on the development of mechanism-specific and molecular test systems. In particular, his fields of research are the investigation of the time-dependent activity of embryotoxic, teratogenic, genotoxic and arylhydrocarbon-mediated effects in early life-stages of zebrafish after exposure to single compounds and complex environmental samples. Another aim of his research is to increase the understanding of molecular processes and the resulting effects in aquatic organisms and in particular in zebrafish after exposure to selected emerging pollutants and their mixtures. 